\title{
The Thread of the Virtual Movement from Wölfflin to Lynn
}

Fabio Colonnese

\begin{abstract}
All buildings move under the effect of physical forces of the earth. It is unperceivable, but they move. Some of them are also designed to move to perform their functions. However, most of them look absolutely still. Nevertheless, architects, critics, and historians of architecture often borrowed terms from scientific disciplines to describe a building or parts of it as if it is actually moving. Since antiquity, artistic literature has been full of »dynamized « descriptions of artwork virtually set in motion to enhance the narrative quality of the communication, but in architecture this happens only from the end of the 18th century onward. Since the end of the 19th century, a sequence of scholars and architects Heinrich Wölfflin, Colin Rowe, Peter Eisenman, and Greg Lynn have been developing a series of analytical and design tools that were used to introduce (or to query) time and motion in architecture, whose different forms are here presented, classified, and discussed.
\end{abstract}

Keywords: Visual Perception; Virtual Movement; Kinetic Architecture; Dynamic Architecture; Heinrich Wölfflin; Colin Rowe; Peter Eisenman; Greg Lynn.

\section{Introduction}

All buildings move. Although this may seem a paradox for works that are designed to provide people with resistant and long-lasting structures made of inert materials, buildings unperceivably move as a reaction to movements of the earth, to wind pressure or to temperature gaps, eventually leaving traces on the architectural envelope (fig. 1). Moreover, all buildings change. Since the day of their occupation, inhabitants start to customize their internal and external components to enhance or update their performance and even major transformations are required over the years, according to criteria and timescales explored by Frank Duffy (1992) and Stewart Brand (1994). 
Some buildings, or parts of buildings, are properly designed to move. They can rotate to follow the sun, like the Villa Girasole in Marcellise, designed by Angelo Invernizzi and Ettore Fagiuoli and built between 1929 and 1935 or the Dynamic D*House designed by David Ben Grünberg and Daniel Woolfson in 2012; they can slide to cover open space, like The Shed recently designed by Diller and Scofidio and built in New York; they can close hermetically to protect their inhabitants, like Robert Konieczny's Safe House built in Warsaw, Poland in 2005-2009; they can open and resemble living creatures, like Santiago Calatrava's Milwaukee Art Museum bird-like extension of 2001; they can change their interiors from day to night, like some of Steven Holl's »hinged spaces« or even their envelope to optimize their environmental performance, like the Arab World Institute in Paris, designed by Jean Nouvel and built in the early 1990s.

Conversely, other buildings are forced to move, as victims of urban redevelopment or spoils of war, colonization, or megalomania, like the Spanish monastery of Miami, Florida (Colonnese/D'Amelio/Grieco 2021).

In the late 1960s, inspired by the results of artistic research by Alexander Calder and other artists, Frank Popper (1968) proposed a classification of the works of art that are dealing with movement. He divided the "plastic arts« into »static « and »kinetic « arts and the movement into »real« and »virtual« movement, which somehow occurs in the eye and mind of the beholder. While architecture can generally be considered as a »static plastic art", the before-quoted buildings provide proper examples of what Popper defines as »kinetic architecture«.

This article is rather addressed to the »virtual« movement that architecture can produce when it is intended as a representation. While architecture is occasionally represented in motion, from the architects dressed as their buildings at the 1931 Waldorf Astoria Beaux Arts Ball to the city bending in Christopher Nolan's Inception, real architecture can be designed to suggest an effect of motion. Architects' interest in virtual movement is revealed not only by some of their drawings - think of the growing importance of diagrams and the envisioning of intangible phenomena (Colonnese 2012) - but also by the terminology and metaphors that architects, critics, and historians of architecture adopt to describe buildings that look absolutely still. This article compares it to the technique of the description of works of art since antiquity, individuating the »dynamization « as a shared approach. In particular, it focuses on the contribution of Heinrich Wölfflin (1864-1945) in stressing the role of architecture in expressing itself as an epiphany of forces fighting 
each other, eventually denoting the virtual movement of the parts as a deformation resulting from this conflict. At the same time, while describing the different forms of the virtual movement of architecture, it focuses on the contribution of Colin Rowe (1920-1999), Peter Eisenman ("1932), and Greg Lynn ("1964), who are mutually connected in developing Wölfflin's ideas over three generations and in suggesting different interpretations of movement. The article compares the "animated « architecture, whose form is a function of the adaptive motion induced by the context, with the virtual kinetic architecture, in which the observer connotes the motion. It then classifies several types of virtual movement - simple motion, superimposition, transformation, and processual movement - according to Rowe's concept of "phenomenological transparency« (1976: 159-184).

\section{Dynamizing the Description}

The process of »temporalization« or »dynamization« is a rhetorical technique that consists in organizing the description or hypotyposis of a work of art over time through movement. This attitude is already perceived in Philostratus's ekphrasis of ancient, lost artworks (Shaffer 1998), in which, as Mengaldo notes, »the description of the work does not mimic the work but the gaze that runs through the work « (2005: 38, author's translation). In addition to the gaze, the writer can animate the image itself, giving it a virtual movement. For example, in The Lives, the historian Giovanni Pietro Bellori describes an annunciation depicted by Federico Barocci like a movie. He wrote that:

»Pausing in sudden surprise, the Virgin kneels with lowered eyes and opens her right hand in meek wonderment, resting the other on the desk with her book. The angel before her bends one knee and rests his left hand with the lily on the other; and extending his right hand toward her serenely, he reverently announces the divine mystery« (Wohl 2005: 165).

Michele Cometa recalls that:

»The desire to set the image in motion cannot be limited in the age of cinema, but rather it is a desire (and a fear) that has been addressing the whole anthropology of the image, at least in the West, since its inception « (Cometa 2012: 46, author's translation). 
- 
1.

The weaving windows of the second floor of the

Palazzo Borghese in Rome after centuries of pressure and subsidence. Palazzo Borghese, Rome, end of 16th century. Photographer: Fabio Colonnese, 2015. 
In the "complex iteration between images, gazes that rest on these images, and media devices that make this meeting possible« (ibid.: 44, author's translation), both the reader's media experiences, and the physical ones are fundamental. Often, to convey the hypotyposis, the text must induce the reader to collaborate by referring to personal visual experiences. As Umberto Eco proves, this technique »activates not only preexisting cognitive schemes but also preexisting bodily experiences (Eco 2005: 208).

This seems to be fundamental for architecture, which is designed to welcome, protect, and serve the human body. Moreover, architecture has many points in common with literature. Buildings cannot be perceived instantly but must be observed from various points of view and explored in a linear way, like reading a text (Forty 2004: 39), or rather a hypertext. Large and complex buildings have not only been described following the gaze of a hypothetical beholder along the sequence of their interior rooms or the different levels of elevation, but also by attributing movement to the parts and »animating « the inert bodies of the architecture.

However, this kind of description, which requires an audience able to share the experience and sensations, only emerges in the literature of architecture around the 18th century. It seems that as long as architecture had been conceived as the idea of man as a divine expression, the relationship between the human body and the architectural body, in terms of analogy and proportion, was implicit. This link would be testified to by the Vitruvian tradition (Zöllner 2014); by Antonio Averlino known as Filarete, who defines the client and the architect as the father and mother of the project (Filarete 1972: I, 40); by the anthropomorphic figures Francesco di Giorgio Martini associated with his architectural designs (Millon 1958); and by the many terms borrowed from human and animal anatomy to identify the parts of a building (body, arms, wings, and so on) (Colonnese 2016). After the Renaissance, the development of the idea of man as a biological machine, increasingly oriented toward his physical performance, is accompanied by a mathematical and mechanical conception of the architectural project, which is reduced to a typological scheme of preconfigured shapes to be assembled on a grid. In this passage from the organic paradigm to the industrial paradigm, somehow the anima of architecture shifts from a symbolic key to a visual and psychological key, also through the mediation of writing and metaphor.

In his essay »Character and Composition«, Colin Rowe identifies the origin of a new sensitivity toward the topic of movement around the 18th century when, parallel to the emergence of the new aesthetic categories of 
the picturesque, a debate between »composition « and »character« took place in the academies (Rowe 1976:59-88). On the one hand, the value of a building was defined by geometric and distributive criteria; on the other, its value resulted from how it affected the beholder. The movement is a key element of the effect. As the picturesque composition of the gardens shapes the architectural interiors, the subject is called to a continuous movement along waving paths and shifted rooms, and somehow this movement pervades the building itself.

Robert Adam is the first to write openly about movement associated with composition, in a footnote in the preface to his Works in Architecture (1778), where he states:

»Movement is meant to express, the rise and fall, the advance and recess, with other diversity of form, in the different parts of a building, so as to add greatly to the picturesque of the composition. For the rising and the falling, advancing and receding, with the convexity and concavity and other forms of the great parts, have the same effect in architecture, that hill and dale, fore-ground and distance, swelling and sinking have in a landscape: that is, they serve to produce an agreeable and diversified contour, that groups and contrasts like a picture, and creates a variety of light and shade, which gives great spirit, beauty and effect to the composition«(Adam, 1980: I, 1, note 1).

As evidenced by Miranda Hausberg (Hausberg 2019: 340), such a definition is reminiscent of Adam's unpublished essay of 1762 »Of the Elevation and its Movement (Fleming 1962: 315-319), in which the British architect indicated the landscape as a key to regenerate architecture and the landscape paintings as examples for learning about the disposition of forms and the position of the spectator. One could also conjecture that temporalizing the description of a landscape painting was a key to attribute movement to architecture. Anyway, for Adams, virtual movement was a literary device for »animating« the architecture, to give it back an anima.

\section{Dynamizing Architecture}

Since the second half of the 19th century, art history, aesthetic reflection, the psychology of perception, and the physiology of vision have been sharing subjects and methods, implicitly seeking for mutual legitimacy. By the end of the century, inspired by Robert Vischer's Theory of Empathy, which correlates 


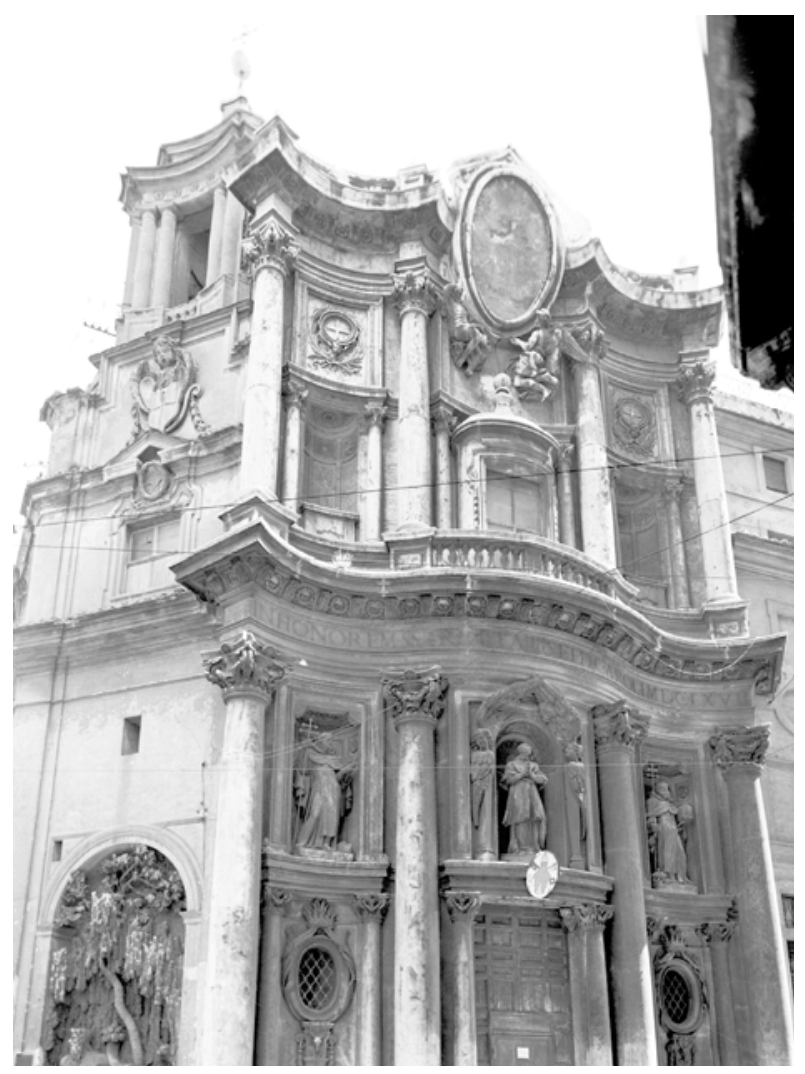

2.

Francesco Borromini: facade of San Carlino alle Quattro Fontane, Rome, 1644. Photographer: Fabio Colonnese, 2015. 
the perceived form with the mood and culture of the subject, the German art historian Heinrich Wölfflin developed his theory of the empathic experience of architecture (Wölfflin 1886). His theory is based on the visibility and judgment that people assign to objects and space not only according to proportions and dimensions, but also in conjunction with their own body and psyche. For example, he argues that the ratios between base and height relate to the characteristics of strength and weight, and effort and rest, whose ideas come from the personal experience of the observers and produce judgments that are analogous to the human and organic. According to Wölfflin sthe importance of form is not the shape, but the breath of life that brings frozen forms into dynamic motion « (Wölfflin 1923: 145, in: Jarzombek 1994: 31).

In his studies on Renaissance and Baroque architecture, Wölfflin »was not interested in the actual forces present in the building, but in how the architecture communicates to the observer the sensation of feeling the compression of the columns, the thrust of the vaults, and so on « (Forty 2000 : 95). To describe the virtual forces affecting the buildings and their effects, Wölfflin introduced terms such as »effort«, "pressure«, "tension«, "relax«, which thereafter became an integral part of architects' vocabulary up to Colin Rowe - in particular his analysis of Le Corbusier's Convent of SainteMarie de la Tourette (Rowe 1976: 185-204), and even further. The integration of these terminologies creates a double effect: on the one hand, they belong to the mechanics of fluids and structures and, by virtue of the distance that scientific disciplines have gradually taken from architecture in the 18th century (Perez-Gomez 1983), they appear capable of clearly illustrating the contents of the architectural experience, eventually attributing a scientific value to the description. On the other hand, as Forty (Forty 2000: 95) recalls, the terms trigger the reader's imagination because they are the same as those that psychology adopts when describing the corresponding emotional states of human beings, who are increasingly associated with the machine (Galimberti 1999).

Wölfflin's interpretation also has the consequence that the architectural form is read as the result of a deformation caused by the acting forces, which promotes the reading of a virtual movement, especially among his followers. According to the Italian historian and architect Paolo Portoghesi, Francesco Borromini saw space as a "rotating vortex, like a tangle of efforts, a tight net« (Pierantoni 1986: 337, author's translation), as exemplified by the facade of the church of San Carlino alle Quattro Fontane (fig. 2): 
»Considered as a field of tensions, which can be defined as a function of movement, this space can acquire a variable density through operations based on complex projective geometry. Newton's observation that the study of circles and lines is a task rather of mechanics than of geometry fits perfectly with Borromini's architecture in which the form is always the result of an operation that presupposes a movement and that potentially expresses it. The constant recourse to the curve line derives from the predilection for bent, curved parts; but always referable to original straight parts« (Portoghesi 1964: 27, author's translation).

The decision to refer the curved elements of the facade to their hypothetical primitive rectilinear configurations is based on the possibility of either seeing, in the same building, or knowing, from the experience of other buildings, similar elements in their straight configuration. By considering the straight element to be in a state of rest, the curved ones can be judged as resulting from a deformation. By relating these deformations to the hypothetical force that generated them, other perceptual and psychological aspects emerge that suggest a further classification of this virtual movement which is also concerned with phenomenology, on the individual considerations of the beholder.

In Borromini's case, the deformation seems to be »elastic « because as the forces cease, tympanums, entablatures, and moldings seem to be able to restore their primitive state of rest. In other cases, the definition of "plastic« deformation seems to be more appropriate. Examples may be found in the Max Reinhardt House designed by Peter Eisenman in 1992, some »collapsed « buildings designed by Frank Gehry, or the Turbulence House designed by Steven Holl in New Mexico in 2005. In 1993, Zvi Hecker conceived the Heinz Galinski school in Berlin as a group of aligned parallelepipeds which, subjected to the action of a twister, slide and are deformed in a spiral shape. Borromini's poetic "vortex« becomes here a real vortex, whose metaphorical passage distorts the buildings in a permanent way. Unlike San Carlino's facade, the Berlin school shares no indication that when the cause ceases the effects can vanish. The deformation is plastic, definitive, irreversible, and the reference to movement shifts to an iconographic level, as architecture becomes the index of a violent event, referring with its shape to a movement that has already ceased. This type of reading is indebted to the operational and iconographic contribution of D'Arcy Wentworth Thompson (1917). In Growth and Form, the Scottish biologist defined form as the diagram 
of forces, the result of the simultaneous action of the internal force of intermolecular cohesion and the external force due to gravity. The irregularities and deformations of the object are considered the organism's response to the environment. In the 1960s, this concept, as well as the potential of diagrams, was assumed by Christopher Alexander to formulate his own definition of form: "If the world were totally regular and homogeneous, there would be no forces, and no forms. Everything would be amorphous. But an irregular world tries to compensate for its own irregularities by fitting itself to them, and thereby takes on form « (Alexander 1964: 15), just like the fish drawn by D'Arcy Wentworth Thompson and deformed according to the underlying grid. Following these suggestions, the American architect Greg Lynn (1999), a pupil of Peter Eisenman, developed the concept of animated design. It is defined by the co-presence of movement and forces at the time of formal definition. This is illustrated in naval engineering, where the shape of a hull is designed by considering water flows, turbulence, and viscosity, or in automotive design, where the body of a car is modeled by studying its aerodynamics in a wind tunnel.

While Eisenman's language is close to Rowe's and the analyses of architectural pieces he has proposed since his famous dissertation (Eisenman 2006) are full of terms expressing the idea of motion in a metaphorical way, Lynn's language is already shaped by the technical vocabulary of informatics, whose mathematical precision replaces the poetic vagueness of the metaphors. Anyway, despite Lynn borrowing the term "animate from animation software terminology (Lynn 1999: 11), it indirectly alludes not only to cartoons - anime is the proper Japanese term for animation movies - but also to animals, whose adaptive strategies had been described by D'Arcy Wentworth Thompson, and to the soul, the anima of living beings, for movement is naturally interpreted as an ancestral sign of life.

\section{A Kind of Motion}

Animated architecture emphasizes the frenetic rituals of human beings. It translates the human habitat into a liquid spatiality defined by curved and sloping surfaces that look unable to create traditional places to inhabit, as evidenced by Herman Hertzberger, but rather puts into focus the idea of continuous movement, a sort of Piranesian labyrinth (Hertzberger 2000: 251). Lynn's approach is antithetical to what he calls the »kinematic model«, in which movement does not influence the architectural form, but it is 


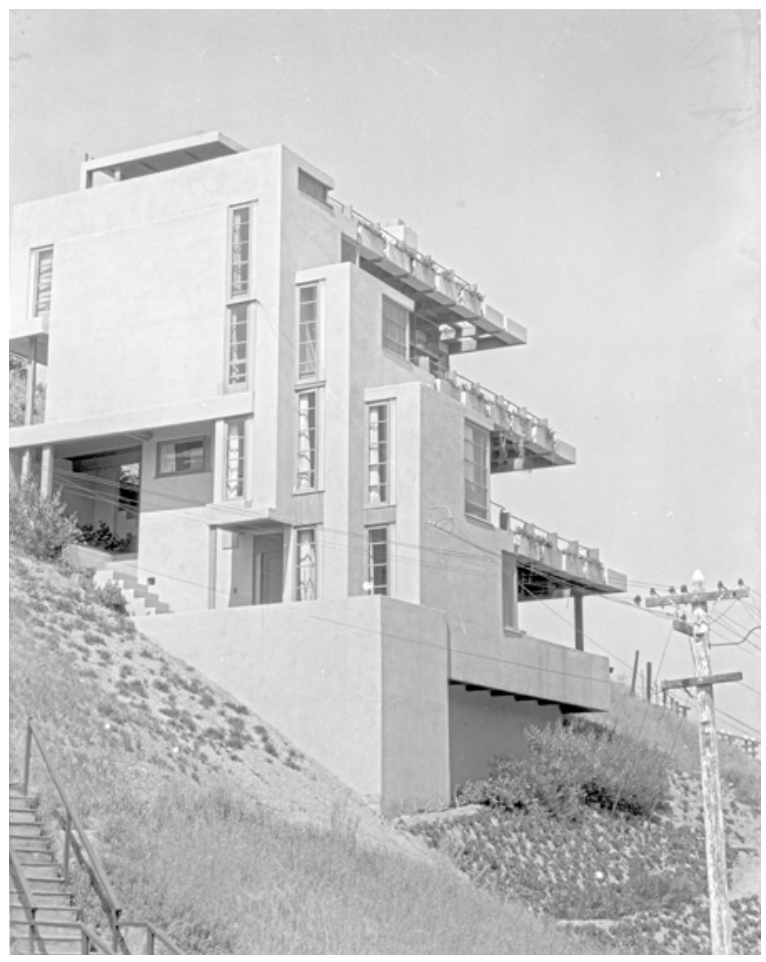

3.

Rudolf Schindler's Wolfe House in Avalon, Santa Catalina Island, California, 1928-31.

Courtesy of the University of California Santa Barbara, Architecture and Design Collection. 
the beholder who adds the motion, largely negotiated by the experience of cinema, through the multiplication and succession of static still images (Lynn 1999: 11). The kinematic model can be considered a general case of the dynamic model discussed before, in which the »vortex« or an alternative system of forces apparently moves the building or only small parts of it. Gravity is the most significant force architects are supposed to deal with but making its presence evident can require some visual artifice, like Giulio Romano's in Mantua.

Christoph Luitpold Frommel writes that Giulio Romano »always suggests the movement, replacing the static condition with a series of dynamic behaviors « (Frommel 1989: 132, author's translation). Once again, the literary question is closely linked to the perceptual question, which constantly oscillates between iconography and psychology. Among the many different movements detected in Palazzo Te in Mantua, the triglyph on the western front appears to be falling. This triglyph's supposed correct location, evidenced by the position of the triglyphs on other facades of the building, is replaced by an empty void, below which the actual triglyph is positioned. The observers superimpose an image taken from their surroundings or their experience of the element actually seen, whose eccentric location is justified through movement. Sometimes, it may be sufficient to take a shape such as the cube, which is commonly attributed to characteristics of stability and tilt it to induce a sensation of movement, as testified to by the composition research of the artistic vanguard of the 1920s and the plethora of studies around the Gestalt theory.

Sometimes, the disposition of a number of similar figures within a narrow field of vision may induce the beholder to group them together in a series. In this case, they can be interpreted as moments of an ongoing movement, up to reconstructing the intermediate positions and producing an illusion of movement by »superimposition« in pseudo-cinematographic terms. From the hill, Rudolf Schindler's Wolfe House, Santa Catalina Island, 1928-31, offered a strong kinetic suggestion (fig. 3). Seen from this exact point of view, the building, which no longer exists, seemed to gradually slide down the slope thanks to the superimposition effect caused by the repetition of the same motif, moved and set back twice. The likeness of the three edges, with the same wall thickness and the vertical windows divided by square frames, is fundamental to inducing the virtual oblique motion along the slope. The eye follows the sequence of the edges, and the gaze moves from the upper to the lower block, giving an effect of movement to the whole structure. 
The virtual movement of architecture is linked not only to the change of form, through the concept of deformation, or to the change of place, through superimposition, but also to the change of state and matter, in the form of metamorphosis. In virtue of the reference to nature as a model to imitate, architects often had the ambition to use the inert material of their buildings to stage a geometric, formal, or even material metamorphosis, from the rocky facades of Gian Lorenzo Bernini to the gradual mutation of the architectural order exhibited by Robert Venturi and Denise Scott Brown in the facade of the new wing of the National Gallery in London.

Sometimes, the metamorphosis does not involve nature and its millennial relationship with architecture but emerges from an introspective gaze on the architectural process itself. Sometimes, the architects intend to represent the process that generated the building as movement from some primitive forms to its complex final configuration. This sort of "processional movement « has developed only in the last century, with the introduction of industrial criteria and the methods of scientific research into architectural production, aspiring to a purely deterministic process. The sophisticated graphic devices that have, for many decades, been illustrating the genetic criteria and steps of architectural projects testify to the growing interest in the process, perhaps to compensate for the semantic deficiency of the International Style products. The representation of the process is not limited to the drawings but sometimes informs the buildings themselves. Deformations, misalignments, colors, materials, frameworks, and bands are used to leave traces of the operations (translation, rotation, insertion, projection, scaling, multiplication, inversion, substitution, metamorphosis, anamorphosis, and many more) developed through models and drawings, generally onto transparent paper (Colonnese 2021).

This kind of movement, and to some extent all the forms of virtual movements of architecture, can be explored through the concept of "phenomenal transparency « Colin Rowe developed in the 1940s together with Robert Slutzky, a visual theorist (Rowe 1976: 159-184). According to Rowe, who was a hybrid between an architect, an art historian, a theoretician and a critic (Vidler 2012: 9), buildings that possess this quality reveal an aptitude for showing two or more contradictory configurations at the same time, in the sense that no evident reading can explain all the elements. It is therefore an optical stratagem that is useful to activate a mental process and, possibly, to bring movement into play as a possible cause of contradictions. In this sense, 
phenomenal transparency can be used to illustrate a building in which the final form reveals the traces of the genetic process that generated it.

Although stimulated by the experience of Cubist art, the concept of phenomenal transparency can be properly considered as an attempt to develop and systematize Wölfflin's procedures. Rowe himself recognized his debt to Wölfflin's method (Vidler 2012: 9); yet at the same time, he criticized it for sacrificing the iconography and giving excessive importance to the visual approach, which eventually promoted its success. Rowe limited his work in the literary field, using the phenomenal transparency as a critical filter that exalted the mannerist and contradictory quality of architecture, which was yet to inspire Robert Venturi and Denise Scott Brown's research. On the contrary, his pupil Peter Eisenman expanded these ideas to built architecture, by investigating the design process as a sequence of movements exhibited not only through descriptions and diagrams but also in the built form. As Stan Allen states, »any time we see work that justifies itself by reference to the history of its design process [...] we are in the territory first mapped out by Eisenman in the seventies with his investigations of the index" (Allen 2006: 63). The series of houses he designed as critical research on the methodology of production and representation of architecture, demonstrate the opportunity to translate architecture into a representation of its own evolutionary trajectory. In Eisenman's critical practice, text and drawing, description and representation somehow touch each other. In 1975, referring to his House IV, Eisenman wrote: »the building is not an object in the traditional sense, not the end result of a process, but more accurately a record of a process, so that the process itself becomes the object « (Eisenman/Gass/Gutman 1994: 23). Eisenman's approach can also be used for retrospective analyses of previous buildings, of course. In this sense, Schindler's Wolfe House can be interpreted both as an ongoing process and the product of the translation of a figure and the fusion of three specific moments along the way.

\section{Conclusions}

The technique of dynamization of the description, through which a virtual movement is applied to the gaze of the beholder and to the figures depicted, was transferred into architecture only around the 18th century, as testified to by Robert Adam's written suggestions coming from the picturesque 
composition. Inspired by Vischer's emphatic approach, the evolution of visual perception studies, and the power of scientific metaphors, Wölfflin contributed to interpret the architectural form as an expression of real or virtual forces affecting the building and to adopt the deformation as a category to illustrate this phenomenon in an "elastic « sense, like in Borromini's architecture, or in a "plastic« sense, like in the metaphor of the catastrophe adopted by some of the Deconstructivist architects. Wölfflin's approach gives a building a temporal dimension that turns a still object into a sort of show going on. Colin Rowe expanded Wölfflin's approach and vocabulary, providing new conceptual tools that can be used to frame different forms of the virtual movement of architecture. In particular, the phenomenal transparency, which considers the coexistence of alternative configurations in the building, uses the time needed to pass from one to another to denote a different kind of movement. Following this suggestion, Peter Eisenman applied the tools of design analysis to connote the building as representative of its design process, using the phenomenal transparency to stage the progressive definition of the final form. Through the mediation of the scientific studies of D'Arcy Wentworth Thompson and the design environment of engineers, Greg Lynn shaped his »animated « approach according to the original dynamic vision offered by Wölfflin but in a pseudoscientific vision, somehow closing the circle. Lynn's approach also has the effect of leading the architectural form back to a purely visual perceptive context, in contrast to the centrality of the proactive enquiry and conjecture required by the virtual movement formulas.

Within this chain of references and interpretations, the role of written language is not only fundamental in deciphering the connotative intents of the scholars and architects but also in producing a sort of metatext framing the architectural process and reception while simultaneously promoting an expanded experience of the virtual movement of architecture. 
References

Adam, Robert (1980[1778]): Works in Architecture of Robert and James Adam, London: Dover.

Alexander, Christopher (1964): Notes on the Synthesis of Form, Cambridge, MA: Harvard University Press.

Allen, Stan (2006): »Trace Elements«, in: Cynthia Davidson (ed.), Tracing Eisenman: Peter Eisenman Complete Works, New York: Rizzoli, 49-65.

Ansari, Iman/Eisenman, Peter (2013): »Interview«, in: The Architectural Review, April 26, 2013, https://www.architecturalreview.com/essays/interview-petereisenman, acessed July 15, 2021.

Brand, Stewart (1994): How Buildings Learn, New York: Viking.

Colonnese, Fabio (2012): Movimento Percorso Rappresentazione. Fenomenologia e codici dell'architettura in movimento (Movement Path Representation. Phenomenology and Codes of Architecture in Movement), Roma: Officina.

Colonnese, Fabio (2016): »Human Figure as a Cultural Mediator in Architectural Drawings«, in: Gülşah Koç/Marie-Therese Claes/Bryan Christiansen (eds.), Cultural Influences on Architecture, Hershey, PA: IGI Global, 90-129.

Colonnese, Fabio (2021): »Transparent Paper as a Modernist Architectural Design Environment«, in: Cristina Bartolomei/ Alfonso Ippolito/Simone Helena Tanoue Vizioli (eds.), Digital Modernism Heritage Lexicon, Cham: Springer, 57-79.

Colonnese, Fabio/D'Amelio, Maria Grazia/ Crieco, Lorenzo (2021): „Sum or Total? The Case of the Cistercian Monastery in Miami«, in: IMG Journal, 4 (forthcoming).

Cometa, Michele (2012): La scrittura delle immagini: letteratura e cultura visuale (Writing Images: Literature and Visual Culture), Milano: Cortina, 2012.
Duffy, Frank (1992): The Changing

Workplace. London: Phaidon Press.

Eco, Umberto (2005): On Literature, Boston, MA: Houghton Mifflin Harcourt.

Eisenman, Peter/Gass, William/Gutman, Robert (1994). »House VI«, in: Suzanne Frank (ed.), Peter Eisenman's House VI: The Client's Response, New York: Whitney Library of Design.

Eisenman, Peter (2006[1963]). The Formal Basis of Modern Architecture, Baden: Lars Müller.

Filarete, Antonio Averlino (1972): Trattato di Architettura (Architecture Treatise), vol. 2, Milano: Il Polifilo.

Fleming, John (1962): Robert Adam and His Circle in Edinburgh and Rome, Cambridge, MA: Harvard University Press.

Forty, Adrian (2004[2000]): Words and Buildings. A Vocabulary of Modern Architecture, London: Thames \& Hudson.

Frommel, Christoph Luitpold (1989): »Le opere romane di Giulio« (The Roman works of Julius), in: Giulio Romano Architetto, Milano: Electa, 96-133.

Galimberti, Umberto (1999): Psiche e techne. L'uomo nell'età della tecnica (Psyche and Techne. Man in the Age of Technology), Milano: Feltrinelli.

Hausberg, Miranda Jane Routh (2019): Robert Adam's Revolution in Architecture. Dissertation, Philadephia, PA: University of Pennsylvania.

Hertzberger, Herman (2000): Space and the Architect. Lessons in Architecture 2,

Rotterdam: 010 Publishers.

Jarzombek, Mark (1994): »De-Scribing the Language of Looking: Wölfflin and the History of Aesthetic Experientialism «, in: Assemblage 23, 28-69.

Lynn, Greg (1999): Animate Form, New York: Princeton Architectural Press. 
Mengaldo, Pier Vincenzo (2005): Tra due linguaggi. Arti figurative e critica (Between two languages. Figurative arts and criticism), Torino: Bollati Boringhieri.

Millon, Henry (1958): »The Architectural Theory of Francesco Di Giorgio«, in: The Art Bulletin 40/3, 257-261.

Pérez-Gómez, Alberto (1983):

Architecture and the Crisis of Modern

Science, Cambridge, MA: The MIT Press.

Pierantoni, Ruggero (1986): Forma fluens. Il movimento e la sua rappresentazione nella scienza, nell'arte e nella tecnica (Forma Fluens. The Movement and its Representation in Science, Art, and Technology), Torino: Bollati Boringhieri.

Popper, Frank (1968): Origins and Development of Kinetic Art, New York: Studio Vista and Graphic Society.

Portoghesi, Paolo (1964): Borromini nella cultura europea (Borromini in European Culture), Roma: Officina.

Rowe, Colin (1976): The Mathematics of the Ideal Villa and Other Essays. Cambridge, MA: The MIT Press.

Shaffer, Diana (1998): »Ekphrasis and the Rhetoric of Viewing in Philostratus's Imaginary Museum«, in: Philosophy \& Rhetoric31/4, 303-316.

Thompson, D'Arcy W. (1917): On Growth and Form, Cambridge: Cambridge University Press.

Vidler, Anthony (2012): »Up Against the Wall: Colin Rowe at La Tourette«, in: Architecture Criticism 24, 7-17.

Vischer, Robert (1873): Über das optische Formgefühl: Ein Beitrag zur Ästhetik (On the Optical Sense of Form: A Contribution to Aesthetics), Leipzig: Credner.
Wohl, Hellmut (2005): Giovan Pietro Bellori: The Lives of the Modern Painters, Sculptors and Architects: A New Translation and Critical Edition, Cambridge: Cambridge University Press.

Wölfflin, Heinrich (1886): Prolegomena zu einer Psychologie der Architektur. Dissertation (Prolegomena to a Psychology of Architecture. Dissertation), Munich: Wolf \& Sohn.

Wölfflin, Heinrich (1923[1915]): Kunstgeschichtliche Grundbegriffe, Munich: Hugo Bruckmann.

Zöllner, Frank (2014): »Anthropomorphism: From Vitruvius to Neufert, from Human Measurement to the Module of Fascism «, in: Kirsten Wagner/ Jasper Cepl (eds.), Images of the Body in Architecture: Anthropology and Built Space, Tübingen/Berlin: Wasmuth, 47-75. 